\title{
Universiteit
}

Leiden

The Netherlands

\section{The foundations of the environmental rebound effect and its contribution towards a general framework}

Font Vivanco, D.; McDowall, W.; Freire-González, J.; Kemp, R.; Voet, E. van der

\section{Citation}

Font Vivanco, D., McDowall, W., Freire-González, J., Kemp, R., \& Voet, E. van der. (2016). The foundations of the environmental rebound effect and its contribution towards a general framework. Ecological Economics, 125, 60-69. doi:10.1016/j.ecolecon.2016.02.006

Version:

Publisher's Version

License:

Licensed under Article 25fa Copyright Act/Law (Amendment Taverne)

Downloaded from: https://hdl.handle.net/1887/43580

Note: To cite this publication please use the final published version (if applicable). 


\title{
The foundations of the environmental rebound effect and its contribution towards a general framework
}

\author{
David Font Vivanco $^{\mathrm{a}, *}$, Will McDowall ${ }^{\mathrm{b}}$, Jaume Freire-González ${ }^{\mathrm{c}}$, René Kemp ${ }^{\mathrm{d}}$, Ester van der Voet ${ }^{\mathrm{a}}$ \\ a Institute of Environmental Sciences (CML), Leiden University, 2300, RA, Leiden, The Netherlands \\ ${ }^{\mathrm{b}}$ UCL Energy Institute, UCL, Central House, 14 Upper Woburn Place, London WC1H ONN, United Kingdom \\ c Environmental Change Institute, University of Oxford, Oxford OX1 3QY, United Kingdom \\ d ICIS and UNU-MERIT, Maastricht University, 6200, MD, Maastricht, The Netherlands
}

\section{A R T I C L E I N F O}

\section{Article history:}

Received 8 September 2015

Received in revised form 25 January 2016

Accepted 21 February 2016

Available online 14 March 2016

\section{Keywords:}

Rebound effect

Consumption

Energy economics

Industrial ecology

Life cycle assessment

Technological efficiency

\begin{abstract}
A B S T R A C T
The study of the so-called rebound effect has traditionally pertained to the domain of neoclassical energy economics. In recent years, other disciplines have applied this concept in the context of the environmental assessment of products and policies, and multiple perspectives have unfolded more or less in parallel. Among these, the environmental rebound effect (ERE) perspective, focused on efficiency changes and indicators that go beyond energy to multiple environmental issues, has remained relatively unnoticed. This article thus asks the following questions: What are the foundational aspects of the ERE and how these relate to other perspectives? Are there irreconcilable differences between perspectives? And what is the value of the ERE towards a general framework? We map the fundamental ideas behind the ERE and find that the lack of articulation has resulted in inconsistent usage and lack of clarity. We also argue that the ERE offers many valuable insights for rebound assessment, such as the study of broader efficiency changes and of innovations aimed at tackling multiple environmental issues. Perhaps most importantly, the ERE helps bringing together the existing rebound perspectives, as its application shows that it is both possible and valuable to articulate broader definitions for the rebound effect.
\end{abstract}

(c) 2016 Elsevier B.V. All rights reserved.

\section{Introduction}

Efforts to reduce environmental burdens by fostering energy or resource efficiency have often fallen short of expectations. One important reason for this is known as the 'rebound effect', which occurs through behavioural and economic demand responses to efficiency changes from technical improvements that are ignored by engineering-based models that apply ceteris paribus conditions (Binswanger, 2001; Brookes, 1990; Greening et al., 2000; Khazzoom, 1980; Saunders, 2005). The rebound effect is generally defined as the difference between the expected and the actual environmental savings from efficiency improvements once a number of economic mechanisms have been considered, that is, the savings that are 'taken back'. An illustrative example is that of improvements in car fuel efficiency, which make driving cheaper and so the liberated income will be spent to drive further distances as well as consuming other products, which in turn will increase energy and fuel consumption.

The rebound effect concept can be traced back to the seminal works of William Stanley Jevons, particularly his much-cited book 'The Coal Question' (Jevons, 1865), from which the so-called 'Jevons Paradox' was derived later on (Alcott, 2005; Giampietro and Mayumi, 1998;

\footnotetext{
* Corresponding author.

E-mail addresses: font@cml.leidenuniv.nl, dfontv@gmail.com (D. Font Vivanco).
}

Wirl, 1997). Jevon's ideas were later embraced by energy economists during the 1980s and 1990s in the context first of a looming energy crisis (1973 oil crisis and 1979 energy crisis) and then concerns over climate change, where the rebound effect was provided with a robust theoretical and analytical framework (Binswanger, 2001; Brookes, 1990; Greening et al., 2000; Khazzoom, 1980; Lovins, 1988; Saunders, 1992). Since then, the rebound effect has gained popularity both in the academic and policy arenas (Maxwell et al., 2011), and academic research and debate of more than 30 years have resulted in a general agreement on its existence as well as a panoply of views about its magnitude and causes (Jenkins et al., 2011; Sorrell, 2007).

The multiple possibilities for analysis that the rebound effect offers also lured other disciplines to adopt it, and each enriched the concept with their own insights. A number of authors have identified different disciplinary perspectives on rebound effects, such as Binswanger (2001); Sorrell (2007); de Haan et al. (2005); Madjar and Ozawa (2006) and Walnum et al. (2014). After carrying out a comprehensive review, Walnum et al. (2014) identify six perspectives that would offer unique understandings of the assumptions and the drivers behind the rebound effect: energy economics, ecological economics, sociopsychological, socio-technological, urban, planning and evolutionary. Moreover, other authors point out the existence of an additional perspective from industrial ecology and sustainability sciences (Font Vivanco and van der Voet, 2014; Hertwich, 2005), known as the 
'environmental rebound effect' (ERE) (Goedkoop et al., 1999; Murray, 2013; Spielmann et al., 2008; Takahashi et al., 2004).

The ERE mainly differs from other perspectives in that the rebound effect concept is generalised to encompass efficiency changes and indicators of interest that go beyond energy and energy-related emissions (mainly $\mathrm{CO}_{2}$ emissions from fuel combustion) to a wide range of environmental issues. This perspective thus incorporates broader efficiency changes as well as the representation of the rebound effect as a multidimensional value into rebound assessments (Font Vivanco et al., 2015). The ERE can be thus defined as the environmental consequences from changes in demand in response to efficiency changes from technical improvement. The ERE also offers other advantages in the context of sustainability assessment, namely, the high technology detail and the life cycle perspective, which are used to calculate more comprehensive estimates of the technology effect driving environmental consequences (see Section 2.2 for a more detailed description). However, a complete investigation of the value of the ERE perspective in rebound effect assessment is missing.

The increasing inclusion of economic and behavioural feedbacks into the analysis of the full environmental impacts of particular technologies has led sometimes to a rather loose use of the term 'rebound effect' (Font Vivanco and van der Voet, 2014). Applications of such type of analysis include economy-environment and economy-energy models as well as life cycle assessment (LCA) and consequential LCA in particular, through which causal effects from marginal changes in technical systems can be appraised (Ekvall, 2002). The progressive broadening of the rebound effect concept thus raises the question of where one draws the line between calling something a rebound effect and simply identifying feedback effects that occur in response to changes in some product or system, and whether such broadening can jeopardise the analytic coherence of the term.

Taking full advantage of the ERE concept thus largely depends on the clear delineation of boundaries for this emerging perspective, and clarifying how it relates to the more narrowly defined 'classic rebound effect', familiar to energy economics. For this, it is key to understand its foundational aspects, including its relationship with other existing perspectives and specific research questions in the context of sustainability assessment. Furthermore, another unresolved issue concerns whether irreconcilable differences exists between the different rebound perspectives, including the ERE, and whether a general, all-inclusive conceptual framework can be delineated. Such a general framework would delineate clear boundaries for the rebound effect rather than offer analytical guidance and aims at favouring learning and co-evolution between disciplines.

In summary, this article addresses two sets of research questions (SRQ):

- SRQ 1: What are the foundational aspects of the ERE? How do these aspects relate to other perspectives and specific research questions?

- SRQ 2: Are there irreconcilable differences between perspectives? What is the value of the ERE towards a general framework?

This paper situates the traditionally defined 'classic rebound effect' within a wider rebound framework, in which we also articulate the strengths and limitations of the ERE concept. In short, that the classical rebound effect relates to changes in energy use (a 'driver' indicator) arising from energy efficiency changes, while the ERE is concerned with the environmental pressure consequences (using 'pressure' indicators) of broader efficiency changes from technical improvements. The distinction between drivers and pressures follows the DPSIR framework of environmental indicators (EEA, 1999), which describes the interactions between society and the environment through driving forces (e.g., energy use), pressures (e.g., $\mathrm{CO}_{2}$ emissions), states (e.g., atmospheric $\mathrm{CO} 2$ concentration), impacts (e.g., temperature rise) and responses (e.g., climate change mitigation policies). The values may greatly differ from one another, even when the key mechanisms are the same: a direct effect, an indirect effect and a macroeconomic systems effect.

The article is organised as follows. Section 2 introduces both the classical and the environmental rebound effect. Section 3 describes the foundations of the ERE perspective by (1) mapping the influences from alternative disciplinary perspectives as well as the novel contributions and (2) justifying such influences and novel contributions in the context of environmental assessment. Section 4 shows the differences and synergies between all rebound perspectives with the aim to explore the feasibility and value of an integrated conceptual framework. Section 5 concludes the paper by discussing the value, limitations and potential impact of the findings.

\section{Origins of the (Environmental) Rebound Effect}

This section is dedicated to the introduction of the mainstream understanding of the rebound effect as well as the environmental rebound effect (ERE) concept and is divided into two subsections. The first subsection provides a basic theoretical framework of the rebound effect as described by energy economics from a neoclassical perspective (from here on referred only as energy economics). The second subsection describes the origins of the environmental rebound effect (ERE) concept, drawing from the works within industrial ecology and other sustainability sciences. The later subsection addresses partly the first set of research questions regarding the foundational aspects of the ERE.

\subsection{The Rebound Effect from Energy Economics}

Energy economics is widely regarded as the cradle of the rebound effect concept. The oil crisis of 1973 and the emergence of worldwide energy efficiency policies revived the insightful yet generally ignored theories of William Stanley Jevons (1865), which postulated that improved energy efficiency would lead to increased economy-wide energy consumption. These ideas were reviewed with renewed enthusiasm through the works of various scholars, among which the contributions of Khazzoom (1980) and Brookes (1990) stood out. The so-called Khazzoom-Brookes postulate (Saunders, 1992) then spurred a panoply of theoretical and empirical contributions within energy economics, which translated into a debate about the theoretical foundations and the importance of the rebound effect that still continues to the present day (Sorrell, 2007). In short, energy economics defines the rebound effect as the reduction in the expected energy savings when the introduction of a technology that increases the energy efficiency of providing an energy service is followed by behavioural and systemic responses to changes in consumption and production factors, mainly prices, income and factors of production (Greening et al., 2000). Such responses can be captured using various analytical approaches, which can be classified into two main groups: those based on direct observation (evaluation studies) and those based on secondary data (mostly based on econometrics) (Sorrell, 2007). Among these, the latter is undoubtedly the most popular among energy rebound analysts, with elasticities playing a key role in rebound effect studies. In short, elasticities use statistical data to measure the responsiveness of economic actors in terms of demand for energy services to changes in the efficiency of providing such energy services. Thus, the more responsive or 'elastic' are economic actors to efficiency changes, the bigger the rebound effect (Berkhout et al., 2000). In mathematical notation, the energy rebound effect (R) can thus be represented as

$R=1+\eta_{\varepsilon_{\mathrm{E}}}^{E}$

with

$\eta_{\varepsilon_{E}}^{E}=\frac{\varepsilon_{E}}{E} \frac{\partial E}{\partial \varepsilon_{E}}$ 
where $\eta_{\varepsilon_{E}}{ }^{E}$ is the elasticity of energy demand (E) with respect to energy efficiency $\left(\varepsilon_{E}\right)$-the percentage of increase or decrease in energy demand associated with a percentage engineering improvement in energy efficiency. In the case of $\eta_{\varepsilon_{E}}{ }^{E}=-1$, that is, engineering predictions of a proportional energy demand reduction due to an increase in energy efficiency, the rebound effect will equal to zero. On the other hand, if $-1<\eta_{\varepsilon_{E}}{ }^{E}<0$ or $\eta_{\varepsilon_{E}}{ }^{E}>0$, the rebound effect will counteract, respectively, partially or fully the energy demand reductions through additional energy demand. In the case of $\eta_{\varepsilon_{E}}{ }^{E}<-1$, the energy savings will be enhanced, a case known as conservation or super-conservation (Saunders, 2005). These basic principles, which are at the core of the rebound effect concept, are channelled through a number of specific economic mechanisms at both the micro and the macroeconomic level. From an analytical point of view, three economic effects are generally recognised within energy economics: direct, indirect and macroeconomic rebound effects (Greening et al., 2000).

Direct rebound effects take place at the microeconomic level of an individual consumer, household or firm as a result of a reduction in the effective price of an energy service, which leads to an increase in the demand for the service. The indirect rebound effect also occurs at the microeconomic level, but it is related to the re-spending and reinvestment effects of the remaining cost savings on other products or production inputs different than the energy service. Some authors also argue that the indirect rebound effect also includes an embodied energy effect, which relates to the indirect energy embodied in the new energy product (e.g., manufacture and installation), the additional spending and the production outputs (Freire-González, 2011; Jenkins et al., 2011; Sorrell, 2007; van den Bergh, 2011). Lastly, the macroeconomic effect results from the aggregate impact of microeconomic effects at a macroeconomic scale, which can drive market price, composition and economic growth effects (Jenkins et al., 2011).

Throughout the rest of the paper, we make a distinction between the 'classic rebound effect' as it is defined and used within energy economics, and the 'environmental rebound effect', a broader concept that we introduce in the subsequent section.

\subsection{The Environmental Rebound Effect}

The study of trade-offs between environmental dimensions as well as the identification of co-benefits and secondary effects arising from technical or policy measures are bread-and-butter issues for industrial ecology and related disciplines (Hertwich, 2005). In this context, the interest by these disciplines in effects related to behavioural and economic responses grew more or less spontaneously. As a result, the rebound effect concept was eagerly adopted, albeit through a variety of understandings. Some authors speak of the 'environmental rebound effect' (ERE), though there is not a widespread agreement on its definition and boundaries. The ERE was originally used by Goedkoop et al. (1999):18 to refer to 'the effect that the world's environmental load increases as an indirect result of a function fulfilment optimisation in both ecological and economic way'. Takahashi et al. (2004) also used the term to describe the additional environmental burdens from a broad set of causal relationships at the microeconomic level, including time and space effects. Spielmann et al. (2008) defined the ERE as the changes in the environmental performance of a system due to the demand corrections with respect to the plain substitution effect when a time saving innovation is introduced. Murray (2013):242 defined the ERE as the "the amount of energy, resources or externality, generated by offsetting consumption, as a percentage of potential reductions where not offsetting consumption occurs'. While all these definitions vary greatly in terms of the scope, drivers and dimension of the rebound effect, they all converge in conceiving the rebound effect as something that relates not only to energy use alone, but to a wide range of environmental consequences. In addition, the ERE perspective is highly influenced by the life cycle thinking (Font Vivanco and van der Voet, 2014), that is, the consideration of the environmental impacts along the entire life cycle of products. Their contribution can thus be interpreted in terms of a broadening of the original rebound effect idea for the purpose of more encompassing environmental assessments rather than a consistent conceptual framework.

While not explicitly using the ERE term, a number of studies have also expressed the rebound effect in one or more environmental dimensions other than energy. For instance, Font Vivanco and van der Voet (2014) identified 17 studies that applied the LCA approach to calculate estimates of the rebound effect in various indicators such as carbon dioxide $\left(\mathrm{CO}_{2}\right)$ and global warming emissions, waste and sulphur dioxide emissions. Moreover, the same study concluded that, by pursuing broader environmental sustainability issues, these and other studies broadened other aspects of traditional energy rebound effect definitions, such as the consumption and production factors or the technical changes leading to the rebound effect. This position would be in line with other arguments such as those from Hertwich (2005) or Takase et al. (2005), which argued that industrial ecology and other sustainability sciences re-interpreted the classic rebound effect definitions in order to fit in other effects of interest that followed the same core principles. However, this reinterpretation has led to sparse and sometimes inconsistent viewpoints. To delineate a theoretical framework for the ERE, it is thus key to understand its foundational aspects. We undertake this task in the following section.

\section{Foundations of the Environmental Rebound Effect}

This section addresses the first set of research questions posed in the introductory section, that is, the linkages between the ERE and other perspectives as well as how such linkages relate to specific shortfalls in sustainability assessment. The underlying aim is to deepen our knowledge of the ERE perspective by describing which aspects have been added (and further developed) from other disciplinary understandings.

We have identified four different perspectives with unique understandings of rebound effects: energy economics, ecological economics, socio-psychological and socio-technological (Binswanger, 2001; de Haan et al., 2005; Madjar and Ozawa, 2006; Sorrell, 2007; Walnum et al., 2014). This classification is similar to that of Walnum et al. (2014) but differs in the fact that the urban planning and evolutionary economics perspectives have been included within the umbrella of ecological economics. The underlying rationale in the case of evolutionary economics is the fact that contributions dealing with rebound issues using evolutionary principles have developed mostly within ecological economics rather than within evolutionary economics as a discipline from mainstream economics. Regarding urban planning, its distinctive trait can be narrowed to the use of time costs as a rebound driver in the context of urban planning and transport studies, and such approach was initially developed within ecological economics as well. In any case, it must be noted that, while a certain degree of arbitrariness is intrinsic to any classification exercise and overlaps may take place, the concept of perspectives is helpful to identify different understandings of the basic rebound effect principle. Following, each perspective is briefly explained and the linkages between each and the ERE are described. It merits noting that, rather than a comprehensive literature review, this section introduces the essential literature underlying each perspective. For a complete review, we refer to the work of Walnum et al. (2014).

\subsection{Energy Economics}

The ERE, as all the other rebound perspectives, has been greatly influenced by the neoclassical energy economics perspective, which established the theoretical foundations behind the classic rebound effect (see Section 2.1) as well as an important body of empirical literature. Concretely, the ERE shares the underlying assumptions from energy economics, that is, that efficiency changes in products from technical improvements (e.g., energy efficiency of providing an energy 
service) can lead to changes in overall demand via behavioural and systemic responses to changes in consumption and production factors. Furthermore, the basic rebound definitions and mechanisms that would capture such responses (see Section 2.1) have also been embraced, although the terminology is not always entirely consistent (see Font Vivanco and van der Voet (2014) for examples).

The interest in such mechanisms by industrial ecologists can be tracked back to the early 1990s when discussing about the effects that could be included in LCA studies (Font Vivanco and van der Voet, 2014). The rebound mechanism was considered of great interest because of the potential to introduce behaviourally realistic demand in comparative studies and thus overcome product-based system boundaries in which the functional unit was generally static and arbitrary. Such a step was in line with the gradual evolution of the field towards the operationalisation of sustainability assessments at the macro level and the progressive inclusion of system dynamics (Guinée et al., 2010; Matthews and Lifset, 2007). Moreover, a number of other aspects have also been incorporated from the energy economics perspective, for instance the interest in the study of the rebound effect in the context of energy services such as heating (see, for instance Takase et al. (2005), and Rajagopal et al. (2011)). Also, the study of changes in prices and income, as well as the use of established economic tools such as econometric analysis, household demand models or general equilibrium models (Font Vivanco and van der Voet, 2014). The extensive use of the drivers and tools from energy economics can be explained to a great extent by the existing knowledge base and data availability.

\subsection{Ecological Economics}

Conventional economic theories argue that energy inputs play a secondary role in economic growth, largely because they constitute a small share of total costs (Jones, 1975; Sala-i-Martin, 2002). This perspective has been challenged by scholars from ecological economics, which argue that the productivity of energy inputs is larger than that suggested by its share of total costs, and that the increased availability of high quality energy has been an important driver behind economic growth in the past (Ayres and Warr, 2005; Cleveland et al., 1986; Cleveland et al., 2000; Sorrell and Dimitropoulos, 2007). In the context of the rebound effect, this discrepancy can lead to significantly larger estimates of economy-wide rebound, although there is no uncontested empirical evidence available to support this claim (Sorrell, 2007).

Another line of research within ecological economics deals with the study of rebound effects from an evolutionary perspective (Ruzzenenti and Basosi, 2008). This would be grounded in the idea that social and ecological systems are 'metabolic systems which are organised in nested hierarchical levels and have the ability to evolve simultaneously across different scales to learn' (Giampietro and Mayumi, 2008:91). Such interpretation, according to Giampietro and Mayumi (2008), poses two major challenges to the conventional classic rebound effect: (1) the definition and measurement of energy efficiency becomes more complex, and (2) the difficulty of distinguishing whether changes in energy efficiency arise from changes in technology coefficients or from the profiles of tasks to be performed.

An additional issue that has been studied to some extent within ecological economics relates to the study of time use as a consumption factor, the change of which can lead to the so-called time rebound effects (Jalas, 2002). This approach has been used by different disciplines to study time-efficient technological changes, especially in the transport sector, for instance regarding increased road capacity and traffic management systems (Hymel et al., 2010; Small and Van Dender, 2007).

The multiple insights from the ecological economics perspective have drawn the attention of scholars from sustainability sciences, especially from industrial ecology (Hertwich, 2005), yet empirical studies are scarce in the context of environmental assessment. The inclusion of time use changes as a driver of rebound effects have been progressively incorporated in the context of sustainability assessments, especially of transport systems (Spielmann et al., 2008; Girod et al., 2011). Moreover, while the study of energy quality remains largely unexplored, the inclusion of evolutionary principles is an emerging field of research. For example, Benedetto et al. (2014) argue that an evolutionary view could capture the dynamic adaptation of the markets to the new attributes (e.g., improved carbon footprint) of existing products and technologies, and that CLCA could be suitable analytical framework due to the capacity to better study dynamic responses from the market, such as the adaptation to new structures. Another approach to apply the evolutionary view is through agent-based modelling (ABM), which is based on computational and microscale models that allow to capture emerging properties of complex and adaptive systems through the simulation of the actions and interactions of autonomous agents (Billari et al., 2006; Faber and Frenken, 2009). Hicks and Theis (2014) and Hicks et al. (2015) applied ABM in combination with LCA and simulated emergent behaviour responses of households to the adoption of energyefficient lighting technologies, including the direct price rebound effect.

\subsection{Socio-psychological}

A reinterpretation of the neoclassical economic theories of consumer behaviour used in energy rebound studies favoured the theorisation of what has been coined as 'socio-psychological' or 'mental' rebound effects $^{1}$ (de Haan et al., 2005; Girod and de Haan, 2009). This alternative perspective is based on two main ideas. First, consumption is not fully explained by income levels and prices, but it also has a social and cultural dimension (Hofstetter and Madjar, 2003; Jackson, 2005). Thus, consumption would imply costs that are culturally and socially defined, including environmental values and attitudes. Second, consumers and firms do not have full information about the costs of products and do not always opt for optimal solutions to price changes as neoclassical economic theory assumes. Thus, the neoclassical models of consumer behaviour that predominate microeconomic analysis of energy rebound (Berkhout et al., 2000) would not be able to fully explain consumer choices leading to rebound (Woersdorfer, 2010).

The ideas underlying the socio-psychological rebound perspective were received with enthusiasm within sustainability sciences, since they allowed to explain effects beyond pure price and income mechanisms and with a higher behavioural realism that were of interest for the study of sustainable consumption and lifestyles. For instance, Weidema et al. (2008) studied the rebound effect from changes in six consumption factors which were previously described by Hofstetter and Madjar (2003): money, information, resources, space, time and skills. By including additional economic drivers, the authors could study more comprehensively the drivers behind changes in demand along the life cycle of products and ancillary systems, for instance shifts in the timing of activities, the reduction of road congestion and the changes in car-ownership. Additional consumption factors identified within sustainability sciences include: socio-psychological costs (de Haan et al., 2005; Madjar and Ozawa, 2006), technology availability (Weidema and Thrane, 2007) and technical definitions (de Haan, 2008).

\subsection{Socio-technological}

The socio-technological perspective is primarily based on the idea that changes in technology have the potential to introduce transformative changes in society, for instance 'change consumers' preferences, alter social institutions, and rearrange the organization of production' (Greening et al., 2000:391). In contrast with the previous perspectives, it goes beyond marginal changes in actor's demand by introducing long-scale and persistent changes in society. Such critical societal

\footnotetext{
1 The term 'psychological' rebound effects has also been used in the literature, for instance in the works of Madjar and Ozawa (2006) and Santarius (2012). We, however, prefer the label 'socio-psychological' as, following the reasoning of de Haan et al. (2005), it incorporates the cultural dimension.
} 
changes would translate into 'transformational' (Greening et al., 2000) or 'frontier' (Jenkins et al., 2011) effects, which would complement the existing classical rebound effect literature (see Section 2.1). However, as Greening et al. (2000):399 point out, the 'extension of the rebound definition to include transformational effects is conceptually possible but not analytically practical since both theory and data for such predictions are lacking', and 'attempting to assign causal linkages between changes in society and changes in energy efficiency, without addressing all of the potential confounding factors, would likely lead to unsupported and incorrect conclusions'. Because of this, clear definitions and boundaries for these effects have not been developed so far, and they are the focus of an ongoing debate (Jenkins et al., 2011).

Scholars from sustainability sciences have embraced with great interest the underlying ideas behind the socio-technological perspective and have regarded them as highly important (Hertwich, 2005; Plepys, 2002). In the context of CLCA, transformational effects are of interest since they enable analysis of the consequences of decisions on product and technology adoption in the long term. More broadly, the study of long-term effects can be useful to support strategic technology choices on sustainability grounds. In a bold attempt to study these transformational effects, Sandén and Karlstrom (2007) applied the CLCA approach to analyse long-term effects from the adoption of fuel cell buses. The authors applied theories of path-dependent technical change through learning curves to describe changes in the availability and cost of technologies as well as in actor's preferences as a result of the cumulative build-up of stocks and structures. Similar approaches can be found in the works of Kushnir and Sandén (2011) and Hillman (2008).

\section{Differences and Synergies: Towards a General Framework}

This section addresses the second set of research questions stated in the introductory section and aims to describe the conflicting and the converging points between the ERE and other rebound effect perspectives-particularly the classic rebound effect-and to identify whether an all-inclusive framework can be developed. Moreover, the role and value of the ERE perspective in this harmonisation process is also discussed. The reasons to build a general framework, which in turn will frame our discussion, are as follows: (1) convergence: a common language could favour learning and co-evolution between disciplines; (2) value: a broad applicability of the rebound effect framework in the context of the study of environmental and broader sustainability issues could favour the identification and study of relevant effects; and (3) communication: a straightforward communication to broader audiences may increase the visibility and relevance of the rebound effect issue.

In order to discuss the differences and synergies between the various perspectives of rebound, the definition of rebound effects is decomposed into a sequence of four steps: (1) the efficiency change (rebound trigger), (2) the changes in consumption and production factors caused by the efficiency change (rebound drivers), (3) the economic mechanisms that translate the changes in rebound drivers into changes in demand (rebound mechanisms) and (4) the economic and environmental indicators through which the changes in demand are expressed (rebound indicators) (see Section 4.7 for further details). Two additional aspects outside the definition will also be discussed: the sign of the rebound effect and the original analytical methods applied. The characteristics from these six aspects that are agreed upon all perspectives are summarised in Table 1, whereas those that are not will be discussed ahead in this section.

The first six subsections (Sections 4.1-4.6) of this section are dedicated to the discussion of the differences and synergies for each aspect, including rules to ensure that all perspectives are fully integrable. Section 4.7 concludes by bringing together the main insights drawn and discusses the possibilities for a general, all-inclusive framework.
Table 1

Main characteristics that are agreed upon among all rebound effect perspectives.

\begin{tabular}{ll}
\hline $\begin{array}{l}\text { Efficiency changes-rebound } \\
\text { triggers }\end{array}$ & $\begin{array}{l}\text { Improvements in the ratio between technical } \\
\text { inputs and outputs (economic services)-'process } \\
\text { efficiency' }\end{array}$ \\
\hline $\begin{array}{l}\text { Changes in consumption and } \\
\text { production factors-rebound } \\
\text { drivers }\end{array}$ & Prices, income and factors of production \\
Rebound mechanisms & $\begin{array}{l}\text { Direct (income/output + substitution), indirect } \\
\text { (re-spending/re-investment) and macroeconomic } \\
\text { (market price + composition }+ \text { growth) }\end{array}$ \\
Rebound indicators & $\begin{array}{l}\text { Economic indicators (e.g., income and GDP) and } \\
\text { energy use } \\
\text { Positive }\end{array}$ \\
\hline
\end{tabular}

\subsection{Efficiency Changes-rebound Triggers}

Within the classic rebound effect, but also in other perspectives such as ecological economics, the efficiency changes have generally focused on a rather 'engineering' definition of efficiency, understood as the ratio between technical inputs (e.g., use of energy or other resources) and outputs (economic service) for a given economic service. However, alternative definitions of efficiency from technical change have been proposed in the context of rebound assessment. Two main differing points can be observed: the definition of efficiency itself and the object of the efficiency change. Regarding the former, some scholars applying the ERE perspective argue that changes in the technological characteristics of a product can also lead to a rebound effect. For instance, Dace et al. (2014) identified a price rebound effect caused by the increased use of (cheaper) recycled materials in the market due to the implementation of eco-design instruments. In this case, the technical change relates to the inputs (materials used for manufacture) rather than to the ratio between inputs and outputs. Other authors develop broad definitions in order to include technical changes other than strict technical efficiency, and speak of 'product modification' (Girod et al., 2011) and 'improvement options' (Weidema et al., 2008). Thus, a general understanding within the ERE perspective is that efficiency changes from technical improvements relate to both changes in the technical inputs and outputs -'input/output efficiency'- as well as changes in the ratio between fixed technical inputs and outputs - 'process efficiency' (Schaefer and Wickert, 2015). Moreover, within the ERE perspective, it is also understood than rather than resources alone, the emissions and waste generated to provide a given function can also be approached in terms of efficiency - 'environmental efficiency' (Font Vivanco et al., 2014).

With regard to the object of the efficiency change, classic rebound effect definitions have focused on specific goods and services (e.g., light bulbs and luminance), while alternative definitions speak of both products as well as broad technologies (e.g., passenger cars). The key differentiation lays in the definition of a common service or a function, which always involves a certain amount of subjectivity (Greening et al., 2000; Guinée et al., 2002). For instance, it can be argued that improved products are not entirely comparable with their relevant equivalents, since they provide a function as well as fulfil a set of moral values, for example a means to achieve social status or distinguish between social strata (Jalas, 2002). On the other hand, it could also be argued that all products can be compared on the basis that they all can potentially provide the same amount of subjective 'ultimate utility', such as a happiness or quality of life (Hofstetter and Madjar, 2003). In between, a wide range of possible comparisons involve trade-offs related to multifunctionality (Giampietro and Mayumi, 2008), socially framed technical characteristics (e.g., comfort from transport systems) and other causal mechanisms (e.g., self-selection effects). A compromise must thus be met to permit a certain analytical space while keeping a minimum consistency with the underlying ideas behind the rebound effect idea. The ERE perspective, deeply rooted within the life cycle thinking, may provide a solution to 
this conundrum by acquiring the functional comparability from LCA. That is, two or more systems can only be compared if they provide a comparable function. Using this rule, efficiency changes from technical improvements of broad technologies can be compared instead of specific products alone. For instance, two passenger cars with radically different powertrains can be compared on the basis of a common comparable function: personal transport service by car. Such functional comparability can thus provide such consistency. ${ }^{2}$

Moreover, some scholars argue that conservation decisions (reduced consumption) and consumption shifts can also lead to rebound effects, arguing that the economic mechanisms derived from cost-saving measures would be comparable (Chitnis et al., 2014; Murray, 2013; van den Bergh, 2011). However, the inclusion of these options within the rebound effect framework is more problematic because of two main reasons. First, it can be argued that a simple reduction or a shift in consumption does not directly involve a technical change, but a mere change in the total output demanded by consumers. Second, they present an incommensurability issue: the comparability between before and after the decision falters because they provide essentially different functions. Therefore, the link between the studied efficiency change and the change in demand is compromised. In this regard, we propose a rule according to which conservation decisions and consumption shifts should be aligned with a category of causal effects other than rebound effects. While it is true that the same economic mechanisms as those included within the rebound effect framework are in place, the analytical context is certainly distinct.

\subsection{Changes in Consumption and Production Factors-rebound Drivers}

There is not a full consensus between rebound perspectives regarding the drivers than can initiate the rebound mechanisms. Economic drivers related to prices, income and production factors have dominated the research on rebound effects, mainly due to the existing knowledge base from energy economics and the existing data (e.g., price elasticities and expenditure surveys). However, theoretical and empirical analyses from other fields point out to the existence of additional rebound drivers. Concretely, a total of eight additional rebound drivers have been identified within sustainability sciences: information, resources, space, time, skills, socio-psychological costs, technology availability and technical definitions (see Section 3.3). It merits noting that, while these have been theoretically identified, there is weak empirical evidence supporting their autonomous causal effect and definitions remain unclear. In any case, as de Haan (2008):14 observes, 'the definition of the rebound effect for itself does not state that a price signal should be present, it merely builds upon changes in energy demand due to changes in energy efficiency'. In this sense, we propose a rule to broaden the definition of the rebound effect so that it encompasses all those factors involved in consumption and production decisions would solve this discrepancy between perspectives.

\subsection{Rebound Mechanisms}

The decomposition of the rebound effect into single and autonomous effects or mechanisms is more or less accepted, yet some effects are still disputed. Here we focus on two disputed effects: the embodied and the transformational effects (see Sections 2.1 and 3.4, respectively, for a description). The first is disputed by the ERE perspective since embodied pressures do not involve any economic mechanism linking technology and demand and are not triggered by behavioural or systemic responses, but are the result of the technological characteristics of

\footnotetext{
${ }^{2}$ Functional comparability is not without problems. A car-ride is functionally different than a train ride and bike ride. In a train you are driven and you can read a book. People may do a bike ride for health reasons (the function of going from $A$ to $B$ is combined with doing a sport activity). The functional equivalence is always an approximation, which we like the analyst to examine rather than to assume.
}

products as well as upstream and downstream processes, and are thus necessary and inseparable from the improved products (Murray, 2013; Friedrichsmeier and Matthies, 2015). In this regard, we propose a rule to exclude embodied energy and similar effects from the rebound effect framework and treat them as pure technology effects. The consideration of embodied emissions in rebound studies requires of extra modelling layers, yet it offers more comprehensive results by including the indirect emissions associated with efficiency changes (Friedrichsmeier and Matthies, 2015). On the other hand, transformational effects are disputed by various disciplines because of the difficulty to discern the rebound effect itself from other co-production elements (e.g., economic framework conditions and regulations), as already warned by Greening et al. (2000). Indeed, these effects involve wide changes in society that may involve multiple economic, technological, normative and other mechanisms. In this sense, we argue that transformational effects have room within the rebound effect framework only if specific and agreed rebound mechanisms are explicitly identified.

\subsection{Rebound Indicators}

Traditionally, the rebound effect has been discussed in terms of the efficiency with which energy has been used to deliver some service, which subsequently leads to environmental damages. Thus the classic rebound effect is defined in terms of a 'driving force' indicator (according to the DPSIR framework): the consumption of energy. The ERE perspective expresses rebounds in terms of 'pressure' indicators, such as $\mathrm{CO}_{2}$ emissions, arguing that these are closely related with the desired ends, namely, the reduction of environmental impacts on ecosystems and human health. Some authors within the ERE perspective have expressed rebound effects in terms of impacts, such as impact on ecosystems and human well-being (Weidema et al., 2008), taking advantage of the characterisation methods usually applied within LCA. However, the inclusion of impact-type indicators presents the issue of loss of causality with respect to the original efficiency change, since such changes do not aim directly at reducing impacts, but rather at reducing driving forces (e.g., energy use) and pressures (e.g., $\mathrm{CO}_{2}$ emissions). Thus, we suggest to limit the ERE to pressure indicators, rather than driving forces or impacts. In any case, it seems helpful to note that it is such driving forces that 'rebound', since they drive the core rebound mechanisms; the resulting pressures can be understood as the consequences of rebound effects, and it is these consequences that are the focus of the ERE.

The inclusion of indicators other than energy within the rebound effect framework has been the object of a long debate. For instance, Binswanger (2001):120 stated that 'Energy economists [...] have come up with precise definitions of the rebound effect, which can easily be applied to resource use in general'. Building upon this idea, other authors offer similar arguments (Frondel et al., 2009; Giampietro and Mayumi, 2008; Santarius, 2012). In short, while energy use and associated indicators has been the focus of the classic rebound effect, the same economic mechanisms can be applied to other resources. In a similar manner, other scholars argue that these mechanisms would also apply to waste and emissions, that is, to environmental pressures in general (Maxwell et al., 2011; Murray, 2013).

The choice of indicators is not as trivial as it may seem, and has implications beyond expressing the rebound effect as a multidimensional value. It may also condition the efficiency changes that are eligible for study. For instance, under the classic rebound effect, only those changes aimed at improving energy efficiency are generally studied. Under the ERE perspective, the rebound effects from technological innovations aimed at reducing pressures such as GHG emissions or waste via efficiency improvements could also be studied in the context of rebound assessment. This feature also exploits the potential of the ERE perspective for sustainability assessments, for instance regarding innovations that target reductions in multiple environmental pressures. 


\subsection{Sign of the Rebound Effect}

Conventional wisdom suggests that the sign of rebound effects should always be positive for normal goods and services, i.e., that the rebound effect confounds expected environmental savings. However, the progressive inclusion of capital costs in rebound studies (Mizobuchi, 2008; Nässén and Holmberg, 2009) and macroeconomic effects related to negative income, competitiveness and disinvestment (Turner, 2009) has brought up capricious results in the form of 'negative rebound effects'. For instance, when the increase in the capital costs of an improved product offsets the decrease in operation costs, total costs rise and rebound effects become negative. This can be observed, for instance, in the case of electric cars due to the current relatively higher purchasing costs (Font Vivanco et al., 2014).

The concept of a negative rebound effect, though it follows the exact same mechanisms, is certainly counterintuitive, and for this reason some authors have come up with alternative labels such as 'conservation' and 'super-conservation' effects (Saunders, 2005) or 'amplifying' and 'leverage' effects (Spielmann et al., 2008). To summarise, there is no reason to exclude to possibility of negative rebound effects in an all-inclusive framework, though the communication of results to broader audiences may be challenging. Indeed, the rebound effect concept has traditionally been interpreted as the effect of 'rebounding back' from expected savings, yet the same mechanisms can, in some cases, cause a 'rebound forward'. Thus, we advocate the use of alternative labels such as those mentioned above when communicating rebound results to broader audiences.

\subsection{Analytical Methods}

Each rebound perspective has endowed itself with a set of analytical tools that are appropriate to deal with particular research questions. As a result, a panoply of tools are available for rebound analysis, such as econometric tools, ABM, quasi-experimental studies, etc. In the context of a common framework, multidisciplinary approaches would emerge more readily, since different perspectives and their corresponding 'modelling traditions' would be brought together. The ERE perspective provides an adequate example of this since the research of complex sustainability issues becomes futile without a multidisciplinary approach. As a result, multiple combinations of tools from different perspectives can be often observed. Thus, to the combination of traditional economic tools (e.g., household demand models) with environmental assessment tools (e.g., [hybrid] LCA), some authors have added an extra modelling layer by applying methods from the socio-psychological, sociotechnological and evolutionary perspectives (see Section 3).

\subsection{Delineating a General Framework}

Bringing together perspectives from different disciplines is always a challenging task, yet an important one. Our attempt to tackle such challenge is expressed following. We argue that the underlying idea behind all the rebound effect perspectives relates to the study of a number of specific economic mechanisms that link efficiency changes due to technical improvements with demand in the context of the achievement of environmental goals. Such mechanisms would thus be at the core of the rebound effect concept and must be always explicitly identified. The rebound effect can be then broadly defined as a sequence of four steps: efficiency change, change in consumption/production factors, economic mechanisms and indicators (see Fig. 1). Following this sequence, to a given efficiency change in a product or process will follow a change in consumption and/or production factors. This will initiate one or more rebound mechanisms that relate changes in such economic factors with changes in demand, and the change in demand will be then expressed in pre-defined environmental indicators. The choice of indicators will in turn be determined by the specific nature of the efficiency change (e.g., energy efficiency). As it has been shown by analysing the various perspectives, there is not a full consensus regarding the range of options for choosing within every step (e.g., whether consumers react to efficiency improvements only through price changes or changes in prices as well as additional consumption factors), which points out the need for a consistent framework. Moreover, it is important that such a framework is clear and transparent about what is and is not included, so that rebound effects can be distinguished from other effects. It merits noting that Fig. 1 merely makes explicit the various theoretical possibilities for rebound analysis rather than describing a readily applicable analytical framework. The concrete applications of this framework would thus depend on, for instance, data availability and specific research questions. We argue that the main value of this conceptual framework lays in the fact that all rebound perspectives can be integrated in a consistent way. However, as highlighted in the preceding subsections, a number of boundaries and rules are needed to achieve such consistency, which are summarised in Table 2 and further explained following.

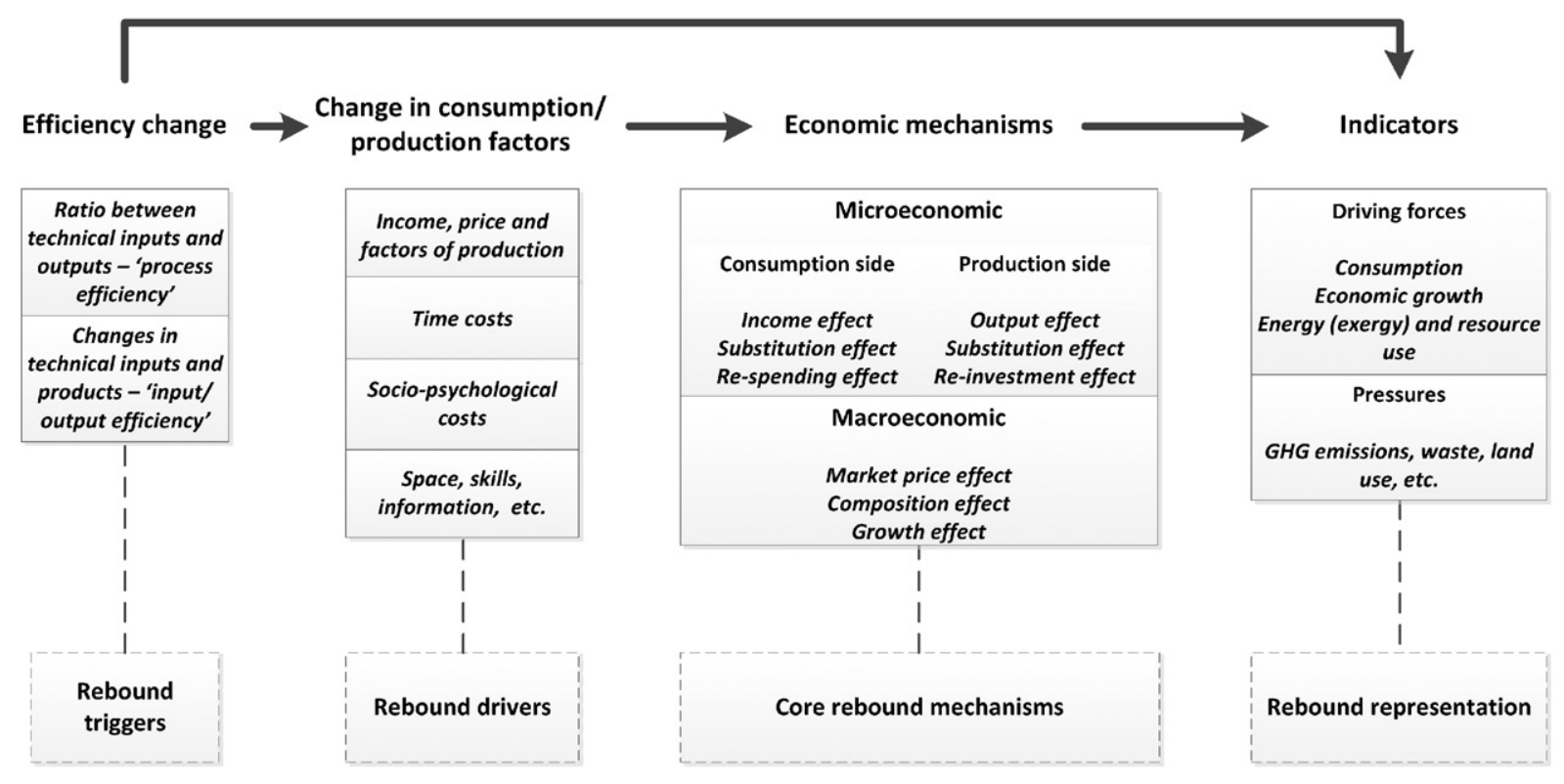

Fig. 1. General framework for the study of rebound effects. 
With regard to the efficiency changes eligible for study, we propose to limit them to changes in the efficiency due to technical improvements but with a broader definition in which efficiency is understood beyond a ratio between fixed technical inputs (resources) and functional outputs in the context of specific products and services. In this sense, we propose to include also changes in the resources used (e.g., the use of a recycled instead of a raw material) as well as the emissions and waste generated to provide a given function. We also propose to broaden the object of the efficiency change to include general technologies (e.g., the change from an internal combustion to and electric engine in a car). Its merits to note, however, that the feasibility of such analyses in the context of the study of the rebound effect is not yet fully tested. We also propose to limit rebound studies to pure technological changes, thus excluding decisions related to reduction and shifts in consumption not induced by efficiency change. Lastly, we propose that an additional rule to ensure functional comparability is needed to strengthen the link between efficiency changes and changes in demand.

Concerning the change in consumption and production factors, we propose a broad interpretation to include any economic factor (understood as necessary inputs for consumption or production activities) that can be related to a consumption or production function in a credible and scientifically sound way. This would include the most-studied prices, income and factors of production, but also time costs, socio-psychological costs and others such as space or volume, skills and information.

With respect to the rebound mechanisms, we propose to maintain those mechanisms with widespread acceptance among rebound scholars, that is, microeconomic effects related to income/output and substitution effects and price-based macroeconomic effects. The underlying rationale is that, through these effects, the changes in demand due to changes in economic factors can be explicitly studied. Other effects such as transformational and growth effects fit conceptually within our proposed general framework, yet may prove challenging to assess from an analytical point of view due to the multiple confounding factors and overlaps with other effects. In this sense, we propose to include them but encourage researchers to explicitly establish the causality with the initial efficiency change from a technical improvement. Moreover, we also propose to exclude embodied-type effects because they are related to the technical characteristics of products and supply chain processes and can be thus considered a pure technology effect.

Regarding the indicators through which the environmental consequences of rebound effects are expressed, we propose to broaden these to any type of pressure-based indicators. We do not recommend to include impact indicators (e.g., impact on ecosystems) because of the fact that efficiency changes do not pursue end-point indicators, but rather reductions in pressures such as GHG emissions or materials. We also propose to include a rule to make environmental indicators eligible only if these are expected or intended to be improved by the efficiency change.

\section{Conclusions}

The classic rebound effect has proven to be a valuable concept within energy economics, helping to inform both analysis and policy. We have argued that an expanded rebound concept, the environmental rebound effect (ERE), is a similarly powerful concept to make the environmental assessment of products and policies more comprehensive and meaningful. For instance, by including multiple environmental pressures as well as indirect effects along value chains. The focus of the rebound effect literature has largely been empirical, and discussions have generally been geared towards whether the size of the rebound effect is small or big (Ruzzenenti and Basosi, 2008). Substantially, less efforts have been put into re-interpreting the conceptual basis of the rebound effect to accommodate new research needs (Woersdorfer, 2010). Even so, alternative perspectives from multiple disciplines are starting to emerge, offering refreshing views on the underlying assumptions and causes behind the rebound effect. The ERE perspective has not, until now, been fully articulated, which has resulted in inconsistent usage and has hampered clarity on the concept.

This article helps to understand the foundational aspects of the ERE by analysing its relationship with other rebound perspectives as well as by comprehensively mapping the novel insights it contributes. We argue that the ERE perspective offers many valuable insights to the general rebound effect framework, such as the multidimensionality aspect and the capacity to undertake broader and more technology-detailed assessments than the classic rebound effect. In the context of increasingly complex environmental challenges, the ERE provides a valuable paradigm to address these. For instance, technological innovation is progressively shifting from addressing single environmental issues (e.g., increases in energy efficiency to reduce oil consumption) towards dealing with multiple issues simultaneously (e.g., electric mobility to mitigate global warming, urban air pollution, noise, etc.) (Elzen et al., 2004). In this case, by expanding the metrics used to determine the efficiency improvements (e.g., from energy alone to GHG or waste) and the indicators, the ERE perspective allows a more comprehensive study of the rebound effects arising from technical change dealing with multiple environmental concerns. This context calls for a reevaluation of the traditional rebound effect theories in order to address such new challenges.

Perhaps most importantly, the ERE can help to bring together the existing rebound perspectives, as its application shows that it is both possible and valuable to articulate broader definitions for the rebound effect in a consistent way and in the context of environmental assessments. Thus, the broader perspective of the ERE helps to understand the rebound effect as a set of core economic mechanisms that various disciplines have applied differently to address particular research questions. Through articulation of the ERE, this paper has attempted to clarify the limits of the rebound concept and its application in the context of environmental assessment, and provide guidelines that strike a conceptually informed and practical balance between breadth and analytic specificity.

\subsection{The limits of the Rebound Effect}

The proposed guidelines for a general theoretical framework must be seen as a contribution towards harmonisation, open to criticism

Table 2

Summary of the proposed rules to achieve consistency between rebound effect perspectives.

\begin{tabular}{|c|c|}
\hline Rule & Explanation \\
\hline Broader definitions of efficiency & $\begin{array}{l}\text { Efficiency is defined as the amount of resources used as well as emissions or waste generated to provide a given function rather than } \\
\text { the ratio between resources and a given product or service alone. }\end{array}$ \\
\hline Technical improvement & A technical improvement must always trigger the change in efficiency, thus excluding consumption shifting and sufficiency actions. \\
\hline Functional comparability & The functions provided by the system before and after the efficiency improvement must be comparable. \\
\hline Broader consumption/production factors & Any economic consumption/production factor that changes as a result of an efficiency improvement can lead to rebound effects. \\
\hline Rebound mechanisms & $\begin{array}{l}\text { Embodied-type effects are not triggered by efficiency improvements and must be considered a pure technology effect rather than a } \\
\text { rebound effect. }\end{array}$ \\
\hline Pressure-based indicators & $\begin{array}{l}\text { Pressure-based indicators can be used to represent the rebound effect, but they are only eligible if these are affected by the efficiency } \\
\text { improvement. Impact-based indicators are excluded since efficiency improvements do not target end-point indicators. }\end{array}$ \\
\hline
\end{tabular}


and re-evaluation as well as further development. In this regard, a number of points remain open for discussion.

First and foremost, the progressive broadening and extension of the rebound concept raises the question of where one draws the line between calling something a 'rebound', and simply identifying feedback effects that occur in response to changes in some product or system. Indeed, by broadening the rebound effect definition, it can overlap with other cause-effect mechanisms (e.g., behaviour and supply chain effects; Miller and Keoleian, 2015), and there is thus a risk that the concept evolves towards a broader but ill-defined causal effect. This phenomenon is already starting to happen within those perspectives that apply a broader definition, such as the ERE, in which the rebound effect is sometimes loosely defined and treated as a mere unintended side effect (Font Vivanco and van der Voet, 2014). A comprehensive debate is thus needed regarding where this 'concept-creep' should end, and where it is no longer analytically useful to understand feedbacks or induced effects as 'rebounds'. The risk is that the term 'rebound effect' becomes catch-all for any effects induced by changes in the environmental profile of a product/service system. Our proposed general framework tries to avoid such risks, first by limiting such broader applications with a number of rules (see Table 2) and, second, by articulating a clear distinction between a narrower 'classic rebound effect', familiar to energy economics, and a broader ERE. It remains to be resolved whether its operationalisation among disciplines will be both useful and feasible.

Second, some analytic applications of the framework remain unclear and would greatly depend on the development of analytical tools and empirical analysis. This limited applicability holds, for instance, regarding consumption and production factors that are difficult to account for (e.g., socio-psychological costs), indicators using complex metrics such as exergy and the appropriate study of emergent properties of systems, among others. The application of this framework to specific case studies will ultimately determine its feasibility and value.

Third, a broader definition can make communication to a general audience more challenging, for instance in the case of 'negative rebound effects' and multidimensional values with differing sizes and signs. Appropriate terminology and classifications would thus become increasingly important, such as the use of alternative labels for 'negative rebound effects'.

Fourth, the eligibility of indicators also presents a venue for debate, since analysing pressures that are not targeted by the efficiency change poses an important question yet to be resolved: Can a given environmental pressure 'rebound' if it was not intended to be improved?

All these open questions prompt a comprehensive debate in which the insights from all the disciplines concerned with sustainability issues must be welcomed. It is not our intention to say the last word in this matter; our aim is merely to show that the term rebound is understood differently; that some of the definitions have big problems of operationalisation, that the combination of different rebound triggers and combination of models for tracking rebound effects and widening the analysis from energy to environmental pressures, constitutes a worthwhile avenue for rebound research.

\section{Acknowledgements}

This research has been undertaken within the framework of the Environmental Macro Indicators of Innovation (EMInInn) project, a collaborative project funded through the EU's Seventh Framework Programme for Research (FP7) (grant agreement no. 283002). The authors want to thank Prof. Paul Ekins, Prof. Peter van Bodegom and three anonymous reviewers for their comments.

\section{References}

Alcott, B., 2005. Jevons' paradox. Ecol. Econ. 54, 9-21.

Ayres, R.U., Warr, B., 2005. Accounting for growth: the role of physical work. Struct. Chang. Econ. Dyn. 16, 181-209.
Benedetto, G., Rugani, B., Vázquez-Rowe, I., 2014. Rebound effects due to economic choices when assessing the environmental sustainability of wine. Food Policy 49 (Part 1), 167-173.

Berkhout, P.H.G., Muskens, J.C., Velthuijsen, W., 2000. Defining the rebound effect. Energy Policy 28, 425-432.

Billari, F.C., Fent, T., Prskawetz, A., Scheffran, J., 2006. Agent-Based Computational Modelling: Applications in Demography, Social, Economic and Environmental Sciences Springer Science \& Business Media.

Binswanger, M., 2001. Technological progress and sustainable development: what about the rebound effect? Ecol. Econ. 36, 119-132.

Brookes, L., 1990. The greenhouse effect: the fallacies in the energy efficiency solution. Energy Policy 18, 199-201.

Chitnis, M., Sorrell, S., Druckman, A., Firth, S.K., Jackson, T., 2014. Who rebounds most? Estimating direct and indirect rebound effects for different UK socioeconomic groups. Ecol. Econ. 106, 12-32.

Cleveland, C.J., Hall, C.A., Kaufmann, R., 1986. Energy and the US economy: a biophysical perspective. Science $225,890-897$.

Cleveland, C.J., Kaufmann, R.K., Stern, D.I., 2000. Aggregation and the role of energy in the economy. Ecol. Econ. 32, 301-317.

Dace, E., Bazbauers, G., Berzina, A., Davidsen, P.I., 2014. System dynamics model for analyzing effects of eco-design policy on packaging waste management system. Resour Conserv. Recycl. 87, 175-190.

de Haan, P., 2008. Identification, quantification, and containment of energy-efficiency induced rebound effects: a research agenda. Rebound research report 1. Eidgenössische Technische Hochschule Zürich, IED-Institute for Environmental Decisions, NSSI-Natural and Social Science Interface.

de Haan, P., Mueller, M.G., Peters, A., 2005. Does the hybrid Toyota Prius lead to rebound effects? Analysis of size and number of cars previously owned by Swiss Prius buyers Ecol. Econ. 58, 592-605.

EEA, 1999. Environmental indicators: typology and overview. Technical report No 25 European Environment Agency.

Ekvall, T., 2002. Cleaner production tools: LCA and beyond. J. Clean. Prod. 10, 403-406.

Elzen, B., Geels, F.W., Green, K., 2004. System innovation and the transition to sustainability: theory, evidence and policy. Edward Elgar Publishing.

Faber, A., Frenken, K., 2009. Models in evolutionary economics and environmental policy: towards an evolutionary environmental economics. Technol. Forecast. Soc. Chang. 76, $462-470$.

Font Vivanco, D., van der Voet, E., 2014. The rebound effect through industrial ecology's eyes: a review of LCA-based studies. Int. J. Life Cycle Assess. 19, 1933-1947.

Font Vivanco, D., Freire-González, J., Kemp, R., van der Voet, E., 2014. The remarkable environmental rebound effect of electric cars: a microeconomic approach. Environ. Sci. Technol. 48, 12063-12072.

Font Vivanco, D., Kemp, R., van der Voet, E., 2015. The relativity of eco-innovation: environmental rebound effects from past transport innovations in Europe. J. Clean. Prod. 101, 71-85.

Freire-González, J., 2011. Methods to empirically estimate direct and indirect rebound effect of energy-saving technological changes in households. Ecological modelling - can we break the addiction to fossil energy? Special Issue, 7th Biennial International Workshop Advances in Energy Studies, Barcelona, Spain, 19-21 October 2010, pp. 32-40

Friedrichsmeier, T., Matthies, E., 2015. Rebound effects in energy efficiency-an inefficient debate? GAIA 24 (2), 80-84.

Frondel, M., Peters, J., Vance, C., 2009. Fuel efficiency and automobile travel in Germany: don't forget the rebound effect. In: Herring, H., Sorrell, S. (Eds.), Energy Efficiency and Sustainable Consumption: the Rebound Effect. Palgrave Macmillan, Basingstoke, UK, pp. 47-68.

Giampietro, M., Mayumi, K., 1998. Another view of development, ecological degradation, and north-south trade. Rev. Soc. Econ. 56, 20-36.

Giampietro, M., Mayumi, K., 2008. The Jevons Paradox: the evolution of complex adaptive systems and the challenge for scientific analysis. The Jevons Paradox and the Myth of Resource Efficiency Improvements, pp. 79-140.

Girod, B., de Haan, P., 2009. GHG reduction potential of changes in consumption patterns and higher quality levels: Evidence from Swiss household consumption survey. Energy Policy 37, 5650-5661.

Girod, B., Haan, P., Scholz, R., 2011. Consumption-as-usual instead of ceteris paribus assumption for demand. Int J Life Cycle Assess. Springer-Verlag, pp. 3-11.

Goedkoop, M., Van Halen, C., te Riele, H., Rommens, P., 1999. Product service systems, ecological and economic basics. Ministry of Housing, Spatial Planning and the Environment, Communications Directorate.

Greening, A., Greene, D.L., Difiglio, C., 2000. Energy efficiency and consumption-the rebound effect-a survey. Energy Policy 28, 389-401.

Guinée, J.B., Heijungs, R., Huppes, G., Zamagni, A., Masoni, P., Buonamici, R., Ekvall, T., Rydberg, T., 2010. Life cycle assessment: past, present, and future. Environ. Sci. Technol. 45, 90-96.

Guinée, J.B., et al., 2002. Handbook on Life Cycle Assessment: Operational Guide to the ISO Standards. Kluwer Academic Publishers, Dordrecht, The Netherlands.

Hertwich, E.G., 2005. Consumption and the rebound effect: an industrial ecology perspective. J. Ind. Ecol. 9, 85-98.

Hicks, A., Theis, T., 2014. An agent based approach to the potential for rebound resulting from evolution of residential lighting technologies. Int. J. Life Cycle Assess. 19 370-376.

Hicks, A.L., Theis, T.L., Zellner, M.L., 2015. Emergent effects of residential lighting choices: prospects for energy savings. J. Ind. Ecol. 19, 285-295.

Hillman, K., 2008. Environmental Assessment and Strategic Technology Choice: The Case of Renewable Transport Fuels Thesis report Department of Energy and Environment, Chalmers University of Technology. 
Hofstetter, P., Madjar, M., 2003. Linking change in happiness, time-use, sustainable consumption, and environmental impacts; an attempt to understand time-rebound ef fects. Final report to the Society for Non-Traditional Technology. Japan/BAO \& Consultrix, Zurich.

Hymel, K.M., Small, K.A., Van Dender, K., 2010. Induced demand and rebound effects in road transport. Transp. Res. B Methodol. 44, 1220-1241.

Jackson, T., 2005. Motivating Sustainable Consumption: A Review of Evidence on Consumer Behaviour and Behavioural Change: A Report to the Sustainable Development Research Network. Centre for Environmental Strategy, University of Surrey.

Jalas, M., 2002. A time use perspective on the materials intensity of consumption. Ecol. Econ. 41, 109-123.

Jenkins, J., Nordhaus, T., Shellenberger, M., 2011. Energy Emergence: Rebound and Backfire as Emergent Phenomena. Breakthrough Institute.

Jevons, W.S., 1865. The Coal Question. An Inquiry Concerning the Progress of the Nation and the Probable Exhaustion of our Coal-Mines. Macmillan and co., Cambridge, United Kingdom.

Jones, H.G., 1975. An Introduction to Modern Theories of Economic Growth. Thomas Nelson and Sons Ltd., UK.

Khazzoom, J.D., 1980. Economic implications of mandated efficiency in standards for household appliances. Energy J. 1, 21-40.

Kushnir, D., Sandén, B.A., 2011. Multi-level energy analysis of emerging technologies: a case study in new materials for lithium ion batteries. J. Clean. Prod. 19, 1405-1416.

Lovins, A.B., 1988. Energy saving resulting from the adoption of more efficient appliances: another view. Energy J. 155-162.

Madjar, M., Ozawa, T., 2006. Happiness and sustainable consumption: psychological and physical rebound effects at work in a tool for sustainable design. Int. J. Life Cycle Assess. 11, 105-115.

Matthews, H.S., Lifset, R., 2007. The life-cycle assessment and industrial ecology communities. J. Ind. Ecol. 11, 1-4.

Maxwell, D., Owen, P., McAndrew, L., Muehmel, K., Neubauer, A., 2011. Addressing the Rebound Effect: A report for the European Commission DG Environment.

Miller, S.A., Keoleian, G.A., 2015. Framework for analyzing transformative technologies in life cycle assessment. Environ. Sci. Technol. 49, 3067-3075.

Mizobuchi, K., 2008. An empirical study on the rebound effect considering capital costs. Energy Econ. 30, 2486-2516.

Murray, C.K., 2013. What if consumers decided to all 'go green'? Environmental rebound effects from consumption decisions. Energy Policy 54, 240-256.

Nässén, J., Holmberg, J., 2009. Quantifying the rebound effects of energy efficiency improvements and energy conserving behaviour in Sweden. Energy Effic. 2, 221-231.

Plepys, A., 2002. The grey side of ICT. Environ. Impact Assess. Rev. 22, 509-523.

Rajagopal, D., Hochman, G., Zilberman, D., 2011. Indirect fuel use change (IFUC) and the lifecycle environmental impact of biofuel policies. Energy Policy 39, 228-233.

Ruzzenenti, F., Basosi, R., 2008. The rebound effect: an evolutionary perspective. Ecol. Econ. 67, 526-537.

Sala-i-Martin, X., 2002. In: University, C. (Ed.), 15 Years of New Growth Economics: What Have We Learnt?Department of Economics Discussion Papers
Sandén, B., Karlstrom, M., 2007. Positive and negative feedback in consequential life-cycle assessment. J. Clean. Prod. 15, 1469-1481.

Santarius, T., 2012. Green Growth Unravelled. How Rebound Effects Baffle Sustainability Targets When the Economy Keeps Growing. Heinrich Boell Foundation and Wuppertal Institute for Climate, Berlin.

Saunders, H.D., 1992. The Khazzoom-Brookes postulate and neoclassical growth. Energy J. 131-148.

Saunders, H.D., 2005. A calculator for energy consumption changes arising from new technologies. Topics in Economic Analysis \& Policy, p. 5.

Schaefer, S., Wickert, C., 2015. The efficiency paradox in organization and management theory. The 4th European Theory Development Workshop. Cardiff, UK

Small, K.A., Van Dender, K., 2007. Fuel efficiency and motor vehicle travel: the declining rebound effect. Energy J. 25-51.

Sorrell, S., 2007. The rebound effect: an assessment of the evidence for economy-wide energy savings from improved energy efficiency. Project Report.

Sorrell, S., Dimitropoulos, J., 2007. UKERC Review of Evidence for the Rebound Effect: Technical Report 5-Energy Productivity and Economic Growth Studies. UK Energy Research Centre, London.

Spielmann, M., de Haan, P., Scholz, R.W., 2008. Environmental rebound effects of highspeed transport technologies: a case study of climate change rebound effects of a future underground maglev train system. J. Clean. Prod. 16, 1388-1398.

Takahashi, K.I., Tatemichi, H. Tanaka, T., Nishi, S. Kunioka, T, 2004. Environmental impact of information and communication technologies including rebound effects. Electronics and the Environment, 2004. Conference Record. 2004 IEEE International Symposium on, pp. 13-16.

Takase, K., Kondo, Y., Washizu, A., 2005. An analysis of sustainable consumption by the waste input-output model. J. Ind. Ecol. 9, 201-219.

Turner, K., 2009. Negative rebound and disinvestment effects in response to an improvement in energy efficiency in the UK economy. Energy Econ. 31, 648-666.

van den Bergh, J.J.M., 2011. Energy conservation more effective with rebound policy. Environ. Resour. Econ. 48, 43-58.

Walnum, H., Aall, C., Løkke, S., 2014. Can rebound effects explain why sustainable mobility has not been achieved? Sustainability 6, 9510-9537.

Weidema, B., Thrane, M., 2007. Comments on the development of harmonized method for sustainability assessment of technologies (SAT). Paper presented at Sustainability Assessment of Technologies, Brussels, Belgium.

Weidema, B.P., Wesnaes, J., Hermansen, J., Kristensen, T., Halberg, N., 2008. In: Eder, P., Delgado, L. (Eds.), Environmental Improvement Potentials of Meat and Dairy Products. JRC Scientific and Technical Reports, Luxembourg.

Wirl, F., 1997. The Economics of Conservation Programs. Kluwer Academics Publishers, Dordrecht, The Netherlands.

Woersdorfer, J.S., 2010. Consumer needs and their satiation properties as drivers of the rebound effect: the case of energy-efficient washing machines. Papers on Economics and Evolution 1016. Max-Planck-Institut für Ökonomik. 